Check for updates

Cite this: Mater. Adv., 2021, 2, 292

Received 10th August 2020, Accepted 2nd November 2020

DOI: 10.1039/d0ma00588f

rsc.li/materials-advances

\title{
Iron-based energy storage materials from carbon dioxide and scrap metal $\uparrow$
}

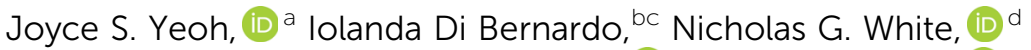 \\ Vincent Otieno-Alego, ${ }^{e}$ Takuya Tsuzuki (D) a and Adrian Lowe (iD) *a
}

\begin{abstract}
The need for sustainable energy storage materials is extremely relevant today, given the increase in demand for energy storage and net zero carbon commitments made recently by multiple countries. In this study, scrap mild steel and carbon dioxide were utilised to synthesise ferrous oxalates, and the feasibility of using ferrous oxalate to store energy and carbon was investigated. Since transition metal oxalates are commonly used as precursors to oxides in the context of energy storage materials, the properties and performance of anhydrous ferrous oxalate were compared with those of iron oxides synthesised from ferrous oxalate. Hydrated ferrous oxalate was synthesised electrochemically from carbon dioxide and scrap mild steel. Subsequent heat treatment of the hydrated material at different temperatures, in both $\mathrm{N}_{2}$ and air, produced anhydrous ferrous oxalate and iron oxides. The products were characterised, carbon content analysed, and their electrochemical performances as negative electrode materials in lithium-ion batteries were investigated. Results indicated that anhydrous ferrous oxalate exhibited the highest gravimetric discharge capacities $\left(810 \mathrm{~mA} \mathrm{~h} \mathrm{~g}{ }^{-1}\right)$, and the highest carbon content $\left(0.28 \mathrm{~g} \mathrm{~A} \mathrm{~h}^{-1}\right)$ when cycled at $100 \mathrm{~mA} \mathrm{~g}^{-1}$. Although the carbon content is low relative to graphite, this study demonstrates that there may be value in further investigating transition metal oxalates as sustainable energy storage materials.
\end{abstract}

\section{Introduction}

The increasing energy demand and the shift towards more intermittent renewable energy sources are currently driving the development of sustainable energy storage materials. While improving the performance of energy storage materials is essential, it is necessary to consider sustainability and environmental impact at all points of their life cycle. ${ }^{1}$ With the increase in momentum towards decarbonising technology and circular economies, it is especially attractive to explore new methods to synthesise materials from waste, using them to store carbon and reducing their carbon footprints.

Lithium-ion batteries (LIBs) are a form of commercially available energy storage, although research into developing

\footnotetext{
${ }^{a}$ Research School of Electrical, Energy and Materials Engineering, The Australian National University, Canberra, ACT 2601, Australia. E-mail: adrian.lowe@anu.edu.au; Tel: +61261254881

${ }^{b}$ School of Physics and Astronomy, Monash University, Clayton, VIC, Australia ${ }^{c}$ ARC Centre for Future Low Energy Electronics Technologies, Monash University, Clayton, VIC, Australia

${ }^{d}$ Research School of Chemistry, The Australian National University, Canberra, ACT 2601, Australia

${ }^{e}$ Specialist Operations, Australian Federal Police, Canberra, ACT, 2609, Australia $\dagger$ Electronic supplementary information (ESI) available. See DOI: 10.1039/ d0ma00588f
}

higher performing and more sustainable materials for them is still ongoing. ${ }^{2}$ Transition metal oxides have received significant amounts of attention as LIB negative electrode materials due to higher theoretical capacities (e.g. $\sim 1000 \mathrm{~mA} \mathrm{~h} \mathrm{~g}^{-1}$ for $\mathrm{Fe}_{2} \mathrm{O}_{3}$ ) compared to conventional graphite $\left(372 \mathrm{~mA} \mathrm{~h} \mathrm{~g}{ }^{-1}\right)$. Transition metal oxides $\left(\mathrm{M}_{x} \mathrm{O}\right)$ are classified as conversiontype materials, where their energy storage mechanism involves the formation of elemental metal (M) and $\mathrm{Li}_{2} \mathrm{O}$ (eqn (1)): ${ }^{3}$

$$
\mathrm{M}_{x} \mathrm{O}+2 y \mathrm{Li} \rightarrow x \mathrm{M}+y \mathrm{Li}_{2} \mathrm{O}
$$

One method of synthesising transition metal oxides is to decompose transition metal oxalates (TMOxs) thermally. The appeal in using TMOxs as precursors stems from the ability to obtain transition metal oxides that are nanostructured and porous. These types of morphology facilitate the effective contact between electrolyte and the internal active material, leading to rapid $\mathrm{Li}^{+}$transportation. ${ }^{4}$ The nanostructures and pores are formed as the oxalate anion $\left(\mathrm{C}_{2} \mathrm{O}_{4}{ }^{2-}\right)$ decomposes into gaseous $\mathrm{CO}$ and $\mathrm{CO}_{2} \cdot{ }^{5-8}$ Incomplete decomposition of TMOxs under certain environments has been shown to yield oxides with carbon residue, leading to better electrochemical performances compared to oxides prepared via complete decomposition in a more oxidative environment. ${ }^{9,10}$ TMOxs are often synthesised in the hydrated form. Considering that reactions 
between water and the lithium electrolyte can be detrimental to the electrochemical performance, TMOxs that are used directly as energy storage materials are typically heat-treated to obtain their anhydrous form. ${ }^{11}$

The direct application of TMOxs as energy storage materials has been investigated to a lesser extent than oxides derived from oxalates, despite the high capacities reported by several groups. $^{12-14}$ TMOxs behave as conversion-type materials, with the formation of metallic particles and $\mathrm{Li}_{2} \mathrm{C}_{2} \mathrm{O}_{4}$ upon reaction with lithium. ${ }^{11}$ While part of the observed capacity arises from the redox activity of the transition metal atoms, studies have shown that the oxalate anion enhances the electrochemical performance of TMOxs. ${ }^{15,16}$ One proposed mechanism for this enhancement relates to the electrochemical participation of oxalate anions, which helps stabilise highly oxidised metal cations, thereby improving electrochemical capacity and durability. ${ }^{15}$

It has been reported that electrochemical capacity increases as cycling progresses for conversion-type electrode materials, including transition metal oxides and TMOxs. ${ }^{11}$ This increase has been attributed to the reversible formation of a polymer gel layer. ${ }^{17-20}$ The polymer gel layer has similar functional groups (carbonates and alkyl carbonates) to a solid electrolyte interface (SEI) and is believed to form via the oligomerization reaction involving carbonate-based solvent molecules in the electrolyte. ${ }^{17}$ Its presence minimises the agglomeration of conversion reaction products $^{18}$ and has the ability to keep active material particles in electrical contact. ${ }^{17}$ The formation of the polymer gel layer contributes to the observed capacity, is believed to have a pseudocapacitive effect, ${ }^{17,18}$ and can re-connect previously electronically isolated materials. $^{21}$

Another advantage of using oxalates is the ability to produce them from $\mathrm{CO}_{2}$. While their formation occurs in nature, ${ }^{22,23}$ oxalates can be produced synthetically via the reduction of $\mathrm{CO}_{2}$ and subsequent dimerisation of $\mathrm{CO}_{2}{ }^{--}$radicals (eqn (2)). ${ }^{24}$

$$
2 \mathrm{CO}_{2}+2 \mathrm{e}^{-} \rightarrow 2 \mathrm{CO}_{2}{ }^{--} \rightarrow \mathrm{C}_{2} \mathrm{O}_{4}{ }^{2-}
$$

Synthesis of other carbon-based molecules (e.g. carbonates, formates, and carbon monoxide) is also possible, with the range and relative quantities dependent on the choice of electrolyte and catalyst. ${ }^{25-27}$ While water is more favourable for improving the sustainability of synthetic processes in general, ${ }^{28}$ it has low $\mathrm{CO}_{2}$ solubility, and its usage favours the formation of formates and carbonates. ${ }^{27}$ Despite these challenges, the formation of oxalates in aqueous electrolyte, with the aid of a $\mathrm{Cr}-\mathrm{Ga}$ oxide catalyst, was recently reported. ${ }^{29}$ Formation of oxalates is favoured in aprotic solvents, making dry acetonitrile an ideal candidate. Acetonitrile, although problematic due to its low occupational threshold limits, is considered the greenest aprotic solvent ${ }^{28}$ and has moderately high $\mathrm{CO}_{2}$ solubility at room temperature. ${ }^{27,30}$ Catalysts used for the electrochemical reduction of $\mathrm{CO}_{2}$ to form oxalates vary widely from sheet metals $(\mathrm{Pb}, \mathrm{In})^{31,32}$ to transition metal complexes $^{33-36}$ designed to improve product selectivity and/or reduce reaction over potentials. ${ }^{33-36}$
Producing oxalates from $\mathrm{CO}_{2}$ and retaining carbon in the product offers the prospect of reducing the product's carbon footprint. Furthermore, electrochemical synthesis methods are attractive from the perspective of milder reaction conditions, higher reaction selectivity, simpler synthesis process compared to some traditional methods used for producing organic molecules and nanostructured energy storage materials. ${ }^{37-39}$ In this study, the electrochemical synthesis of $\mathrm{FeC}_{2} \mathrm{O}_{4} \cdot 2 \mathrm{H}_{2} \mathrm{O}$ from carbon dioxide and scrap ferrous metal (mild steel) is reported. The product was heat-treated under different conditions yielding ferrous oxalates and iron oxides with different carbon contents. The materials were characterised and compared structurally and electrochemically, with a discussion on the values of using oxalates directly or as metal oxide precursors in LIBs. While results demonstrate that $\mathrm{FeC}_{2} \mathrm{O}_{4}$ has higher carbon content and discharge capacity compared to iron oxides prepared from oxalates, challenges common to conversion-type materials remain to be addressed.

\section{Materials and methods}

\section{Electrochemical reduction}

$\mathrm{CO}_{2}$ (BOC, Food Grade, UN1013) was reduced electrochemically in a three-electrode cell with $0.1 \mathrm{M}$ tetraethylammonium tetrafluoroborate (99\%, Alfa Aesar) in dry acetonitrile (99.8\% Anhydrous Sigma Aldrich, 99.5\% Ajax Finechem) as an electrolyte. Acetonitrile was dried over $3 \AA$ molecular sieves (beads 4-8 mesh, Sigma Aldrich). A lead ( $\mathrm{Pb}$ ) metal strip was used as the working electrode, silver (Ag) wire as the quasi-reference electrode and mild steel sheet as the counter electrode/sacrificial anode. A potential of $-2.4 \mathrm{~V} v s$. Ag was applied using a potentiostat (VMP3 Biologic). The amount of charge delivered during electrochemical reduction was monitored, approximately $250 \mathrm{C}$ and $1250 \mathrm{C}$ were delivered when $40 \mathrm{ml}$ and $200 \mathrm{ml}$ of electrolyte were used, respectively, with slight variations depending upon $\mathrm{CO}_{2}$ supply. $\mathrm{CO}_{2}$ was bubbled through the electrolyte for 30 minutes before and during the electrochemical reduction. The surface area of the working electrode $(\mathrm{Pb})$ immersed in 40 and $200 \mathrm{ml}$ of the electrolyte was 2 and $6 \mathrm{~cm}^{2}$, respectively. It is recommended that $\mathrm{CO}_{2}$ is provided in excess. Further increase in the surface area of working electrode is not recommended because of the possible formation of cyano-compounds (see Fig. S1, ESI $\dagger$ ). Potentials below -3.0 vs. Ag may also produce zinc cyanide. ${ }^{31}$

The solid product was isolated by adding deionised water (equal in volume to the electrolyte) and sonicating the reaction mixture, followed by centrifuging (3 repeating cycles of $3500 \mathrm{rpm}$ for 3 minutes), washing with deionised water and drying at $60{ }^{\circ} \mathrm{C}$ for at least 16 hours.

\section{Heat treatment}

Samples were heat-treated in $\mathrm{N}_{2}$ (flow rate $=200 \mathrm{~cm}^{3} \mathrm{~min}^{-1}$ ) at $200{ }^{\circ} \mathrm{C}, 300{ }^{\circ} \mathrm{C}$ and $400{ }^{\circ} \mathrm{C}$ using a tube furnace (SKGL-1200). Heat treatment in air at $300{ }^{\circ} \mathrm{C}$ was performed using a muffle furnace (S.E.M. 102C). Heating rates of $20{ }^{\circ} \mathrm{C} \min ^{-1}$ and $3{ }^{\circ} \mathrm{C} \mathrm{min}^{-1}$ 
were used for the tube furnace and muffle furnace, respectively. The temperatures were held for two hours and the furnace allowed to cool naturally.

\section{Characterisation}

The materials produced were characterised chemically by Infrared (FTIR, Bruker Alpha Platinum-ATR), Raman (Renishaw inVia Raman Microscope, $633 \mathrm{~nm}$ laser at 10\% power), and NMR ( ${ }^{1} \mathrm{H}$ - and ${ }^{13} \mathrm{C}-\mathrm{NMR}$, Bruker Avance 400) spectroscopy. Crystallinity was characterised using powder X-ray diffraction (PXRD) (Bruker D2 Phaser, Cu K $\alpha$ ), phase quantification was performed using Rietveld refinement. Morphology observed using SEM (Zeiss UltraPlus FESEM) and TEM (JEOL 2100F FEGTEM). Elemental analysis was performed via energy dispersive X-ray (EDX) spectroscopy (SEM: Oxford Instruments INCA x-act EDXA, TEM: JEOL JED-2300 $30 \mathrm{~mm}^{2}$ SDD) and CHN analysis (Thermo (Carlo Erba) Flash 2000 Elemental Analyser). Characterisation via thermal decomposition was done by thermogravimetric analysis (TGA) (NETZSCH STA 449 F3 Jupiter). BET surface area was determined using a Micromeritics Tristar II unit. For X-ray Photoelectron Spectroscopy (XPS) analysis, spectra were collected on a Nexsa Surface Analysis System (ThermoFisher) with a monochromated $\mathrm{Al} \mathrm{K} \alpha$ X-ray gun (see $\mathrm{ESI} \dagger$ for further details on XPS analysis).

\section{Electrode fabrication and electrochemical testing}

Products obtained after heat treatment were processed into working electrodes and incorporated into CR2032-type coin cells for electrochemical testing. The working electrodes consisted of $80 \mathrm{wt} \%$ active material, $10 \mathrm{wt} \%$ conductive carbon (TIMCAL Graphite \& Carbon Super P Conductive Carbon Black, MTI) and $10 \mathrm{wt} \%$ polyvinylidene fluoride (PVDF, MW 600000 , MTI). Other cell components included one glass microfibre separator (16 mm diameter, Filtech, grade 363), $1 \mathrm{M} \mathrm{LiPF}_{6}$ in EC/DMC/DEC 4:2:4 vol (MTI) as the electrolyte, and a Li disc (15.6 $\mathrm{mm}$ diameter by $0.25 \mathrm{~mm}$ thick, MTI) as the other electrode. Electrochemical testing was performed using a potentiostat (VMP3 Biologic). Electrodes with active material loadings of $1.4 \pm 1 \mathrm{mg} \mathrm{cm} \mathrm{cm}^{-1}$ and $1.1 \pm 1 \mathrm{mg} \mathrm{cm}^{-1}$ were used for galvanostatic cycling and cyclic voltammetry, respectively. Both types of tests were performed using potential windows of 0.01-3.0 V vs. $\mathrm{Li} / \mathrm{Li}^{+}$. Further details are provided in the ESI. $\dagger$

\section{Results and discussion}

\section{Material characterisation}

$\mathrm{FeC}_{2} \mathrm{O}_{4} \cdot 2 \mathrm{H}_{2} \mathrm{O}$ was successfully synthesised from $\mathrm{CO}_{2}$ and mild steel obtained from a scrap yard, with an average yield of $73 \%$ (see ESI $\dagger$ for calculations). The product was isolated as a solid powder and referred to as "as-isolated". Identification of the asisolated material was made via a combination of characterisation methods (elemental analysis, PXRD, FTIR, Raman, ${ }^{13} \mathrm{C}$ and ${ }^{1} \mathrm{H}$ NMR and XPS analysis). Elemental analysis showed that $\mathrm{Fe}, \mathrm{C}$ and $\mathrm{O}$ were the predominant elements in the sample (Fig. 1a), and the PXRD pattern (Fig. 1b) obtained matched that of $\mathrm{FeC}_{2} \mathrm{O}_{4} \cdot 2 \mathrm{H}_{2} \mathrm{O}$ previously reported ${ }^{13}$ (COD 7218520). Results from FTIR, Raman and ${ }^{13} \mathrm{C}$ and ${ }^{1} \mathrm{H}$ NMR analysis are also in agreement (see Fig. 1c, d and ESI $\dagger$ ). The C1s and O1s XPS spectra (Fig. 2) are also in good agreement with those reported for $\mathrm{FeC}_{2} \mathrm{O}_{4} \cdot 2 \mathrm{H}_{2} \mathrm{O},{ }^{40}$ with additional synthetic peaks (C1s $291.4 \mathrm{eV}$ and O1s $535.2 \mathrm{eV}$, required to obtain a good fit during the peak fitting process) tentatively attributed to traces of $\mathrm{CO}_{2}$ or bicarbonate by-product species. ${ }^{40,41}$

$\mathrm{FeC}_{2} \mathrm{O}_{4} \cdot 2 \mathrm{H}_{2} \mathrm{O}$ thermally decomposes (in $\mathrm{N}_{2}$ ) via two steps (Fig. 1e), the first at $150-200{ }^{\circ} \mathrm{C}(\sim 20 \%$ weight loss $)$ corresponding with the loss of two $\mathrm{H}_{2} \mathrm{O}$ molecules, and the second from the decomposition of oxalate into gaseous species of $\mathrm{CO}$ and $\mathrm{CO}_{2}{ }^{7,8}$ As the oxalate anion decomposes, the material oxidises to products predominantly composed of iron oxides, and a decrease in the sample's carbon content is expected.

Samples of anhydrous ferrous oxalate and iron oxides with different carbon contents were prepared via heat-treatment of the as-isolated material under different conditions. Heat treatment was performed at $200{ }^{\circ} \mathrm{C}, 300{ }^{\circ} \mathrm{C}$ and $400{ }^{\circ} \mathrm{C}$ in $\mathrm{N}_{2}$, and at $300{ }^{\circ} \mathrm{C}$ in air, and products are referred to as $\mathrm{F} 2 \mathrm{~N}, \mathrm{~F} 3 \mathrm{~N}, \mathrm{~F} 4 \mathrm{~N}$ and $\mathrm{F} 3 \mathrm{~A}$, respectively. PXRD patterns matched the reference patterns for $\mathrm{FeC}_{2} \mathrm{O}_{4},{ }^{7,12,13} \gamma-\mathrm{Fe}_{2} \mathrm{O}_{3}$ (COD 9013529) and $\alpha-\mathrm{Fe}_{2} \mathrm{O}_{3}$ (COD 1546383). Analysis of the PXRD patterns, FTIR and Raman spectra indicated that F2N, F3N, F4N and F3A were $\mathrm{FeC}_{2} \mathrm{O}_{4}, \gamma-\mathrm{Fe}_{2} \mathrm{O}_{3}, \gamma-\mathrm{Fe}_{2} \mathrm{O}_{3}$ with ca. $15 \% \mathrm{Fe}$, and $\alpha-\mathrm{Fe}_{2} \mathrm{O}_{3}$, respectively (see ESI $\dagger$ ). Carbon remained present in the samples under all heat treatment conditions, with a decrease in content when heat-treated in air and as temperature increased. The capability of the samples to retain carbon is supported by XPS and $\mathrm{CHN}$ elemental analysis. The $\mathrm{C}: \mathrm{Fe}$ (atomic) ratio extracted from XPS survey spectra (reported in ESI, $\dagger$ Fig. S7) is approximately 2.7, 1.1, 0.9 and 0.7 for F2N, F3N, F4N and F3A respectively, indicating that the surface of $\mathrm{F} 2 \mathrm{~N}$ contains up to three times the amount of carbon compared to F4N. CHN analysis also showed that the bulk carbon content of F2N, F3N, F4N, and F3M is 12.2, 2.1, 0.9, and $0.5 \mathrm{wt} \%$ respectively.

While carbon in each sample was homogeneously distributed instead of being localised to specific grains (see Fig. 3 STEM-EDX), the chemical environment of carbon was different in each sample. Carbon present in F2N and F3N are associated with oxalate anions, and carbon in F4N and F3A attributed to carbonaceous residue from oxalate degradation. The presence of the FTIR peak at ca $1600 \mathrm{~cm}^{-1}$ observed for F3N indicates incomplete oxalate decomposition at $300{ }^{\circ} \mathrm{C}$ in $\mathrm{N}_{2}$, while the lower than theoretical carbon content for $\mathrm{F} 2 \mathrm{~N}$ (16.7 wt\% for $\mathrm{FeC}_{2} \mathrm{O}_{4}$ ) suggests the possibility of some oxalate degradation. Destruction of oxalate carbonyl functional groups in $\mathrm{F} 4 \mathrm{~N}$ and F3A was indicated by the absence of the FTIR peak at $1600 \mathrm{~cm}^{-1}$. Meanwhile, the presence of carbonaceous residue in F3N and F4N was suggested by two Raman peaks (1670 and $1580 \mathrm{~cm}^{-1}$ ) occurring close to the expected Raman shifts for carbon D and G peaks. Although two broad bands in the similar region have been used as identification markers for $\gamma-\mathrm{Fe}_{2} \mathrm{O}_{3},{ }^{42}$ other studies have attributed them to the possible presence of carbon resulting from burnt organic matter ${ }^{10,43,44}$ after finding that their appearance was independent of oxide type. ${ }^{43}$ 

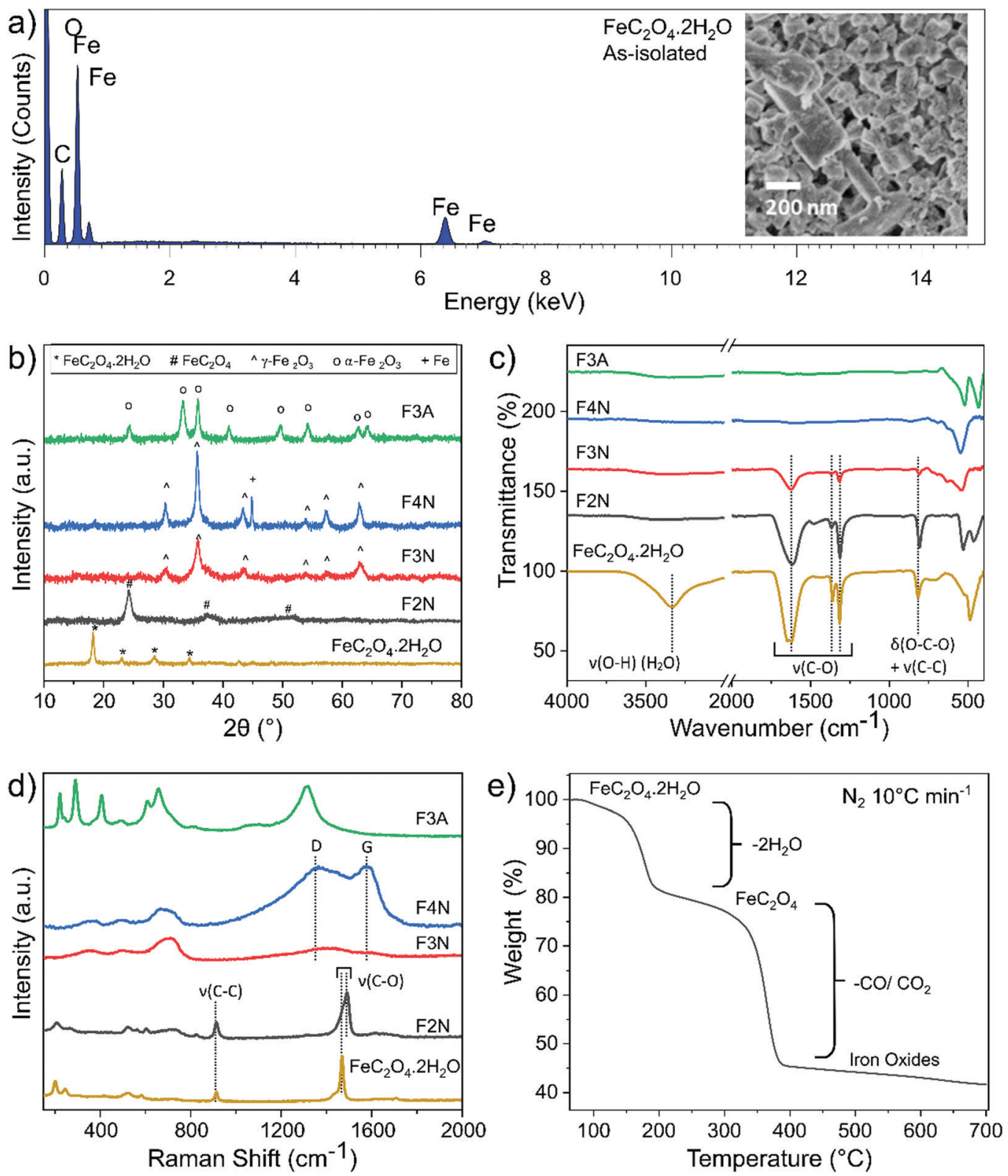

Fig. 1 (a) SEM-EDX spectral data and (inset) SEM image of as-isolated material. (b) PXRD patterns (c) FTIR spectra, (d) Raman spectra of as-isolated and heat-treated $\mathrm{FeC}_{2} \mathrm{O}_{4} \cdot 2 \mathrm{H}_{2} \mathrm{O}$, revealing chemical and structural changes after heat treatment. (e) Weight loss profile of as-isolated FeC $\mathrm{O}_{4} \cdot 2 \mathrm{H}_{2} \mathrm{O}$ during thermal decomposition in $\mathrm{N}_{2}\left(10^{\circ} \mathrm{C} \mathrm{min}^{-1}\right)$.

Differences in the chemical environment of carbon, and the degradation of oxalate anions on the surface of the material as heat-treatment temperature increased, were also supported by XPS results. For F2N, F3N, F4N and F3A, the C1s component (Fig. 2a) can be deconvolved with three synthetic peaks: the first component at $284.7 \mathrm{eV}$ binding energy (BE) is attributed to $\mathrm{C}-\mathrm{C}$ and $\mathrm{C}-\mathrm{H}$ bonds; a second component at $286.4 \mathrm{eV}$ can be ascribed to $\mathrm{C}-\mathrm{O}$ bonds, while the highest BE component at $288.75 \mathrm{eV}$ is attributed to O-C-O bonds. ${ }^{40}$ The relative intensity of the $\mathrm{O}-\mathrm{C}-\mathrm{O}$ to $\mathrm{C}-\mathrm{C}$ peaks decreases as a function of the heat-treatment temperature, indicating that the samples treated at higher temperatures suffer a larger loss of $\mathrm{O}-\mathrm{C}-\mathrm{O}$ groups. The spectra of $\mathrm{F} 4 \mathrm{~N}$ and $\mathrm{F} 3 \mathrm{~A}$, correspond to the C1s lineshape typical of physisorbed impurities on nominally carbon-free samples, ${ }^{45}$ indicating a complete loss of oxalate. These results are in line with Raman spectra, where the $\mathrm{G}$ and $\mathrm{D}$ peak (attributed to $\mathrm{C}-\mathrm{C}$ bonds in the carbonaceous residue) can only be observed for $\mathrm{F} 4 \mathrm{~N}$ and, more faintly, in F3N. The O1s core levels (Fig. 2b) reflect the same scenario: a low binding energy component $(530 \mathrm{eV})$ is detected for all samples and ascribed to the formation of $\mathrm{Fe}_{2} \mathrm{O}_{3}$ compound. ${ }^{46}$ A higher BE peak $(532 \mathrm{eV})$, associated with $\mathrm{O}-\mathrm{C}-\mathrm{O}$ and $\mathrm{C}-\mathrm{O}$ groups, ${ }^{40}$ is observed to decrease in intensity as a function of the annealing temperature of the sample. This component in F3A and F4N is attributed solely to the presence of impurities on the surface of the powders. 

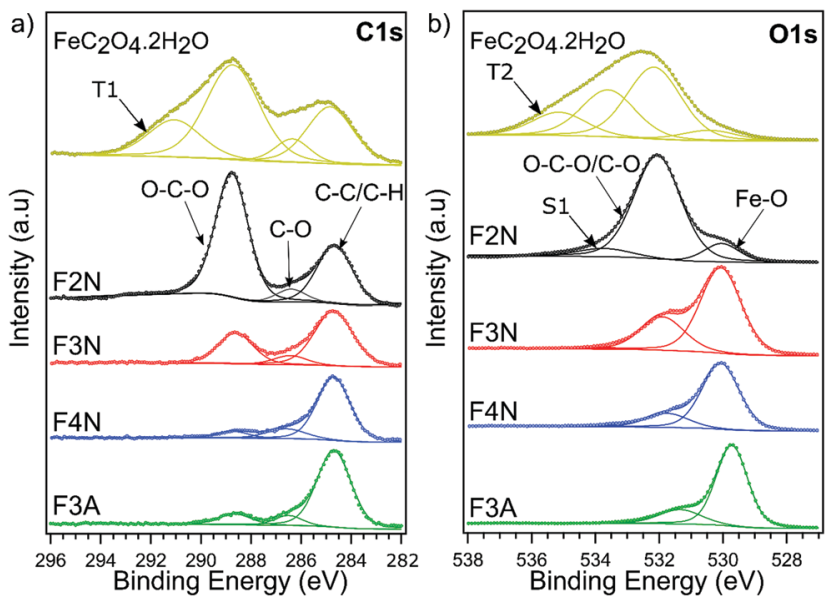

Fig. 2 High-resolution (a) $\mathrm{C} 1 \mathrm{~s}$ and (b) O1s XPS spectra for $\mathrm{FeC}_{2} \mathrm{O}_{4} \cdot 2 \mathrm{H}_{2} \mathrm{O}$, F2N, F3N, F4N and F3A. Spectra are vertically offset for clarity, and the deconvoluted components corresponding to key chemical groups are indicated. The component $\mathrm{S} 1$ is assigned as a satellite structure, ${ }^{40}$ and components labelled $\mathrm{T} 1$ and $\mathrm{T} 2$ tentatively assigned to $\mathrm{CO}_{2}$ and bicarbonate species.

Morphologies of heat-treated samples are shown in Fig. 3. F2N had a porous structure similar to that published recently (see ESI, $\dagger$ Fig. S8), ${ }^{14}$ and a surface area of $89 \mathrm{~m}^{2} \mathrm{~g}^{-1}$. Oxide samples (F3N, F4N, F3A) consisted of plate-like particles, of which F4N had the largest particles (surface area of $42 \mathrm{~m}^{2} \mathrm{~g}^{-1}$ ). F3N and F3A consisted of smaller particles and had higher surface areas of 111 and $115 \mathrm{~m}^{2} \mathrm{~g}^{-1}$, respectively. The smaller specific surface area and sharper PXRD peaks observed for F4N, compared to F2N and F3N, suggest changes to the crystallinity of the products, with the formation of larger crystallite sizes at higher temperatures.

\section{Electrochemical reactivity and cyclability}

Galvanostatic cycling was performed at different current densities (50-400 $\mathrm{mA} \mathrm{g}^{-1}$ ) to assess the cyclability of each material. Fig. 4a shows the specific discharge (lithiation) capacity with respect to cycle number. After 50 cycles at $100 \mathrm{~mA} \mathrm{~g}^{-1}$, F2N exhibited the highest capacity ( $767 \mathrm{~mA} \mathrm{~h}^{-1}$ at 50th cycle). The capacity increased to $880 \mathrm{~mA} \mathrm{~h} \mathrm{~g}{ }^{-1}$ when cycled at slower current densities ( $50 \mathrm{~mA} \mathrm{~g}^{-1}$ at cycle 55). Heat treatment under $\mathrm{N}_{2}$ at higher temperatures and in air, producing iron oxides, led to lower capacities; 370, 261, and $112 \mathrm{~mA} \mathrm{~h} \mathrm{~g}^{-1}$ were observed for F3A, F3N, and F4N respectively at the 50th cycle $\left(100 \mathrm{~mA} \mathrm{~g}^{-1}\right)$. The high capacity exhibited by F2N was retained after cycling at faster rates $\left(200,300\right.$, and $\left.400 \mathrm{~mA} \mathrm{~g}^{-1}\right)$, with a discharge capacity $810 \mathrm{~mA} \mathrm{~h} \mathrm{~g}{ }^{-1}$ delivered at cycle $230\left(100 \mathrm{~mA} \mathrm{~g}^{-1}\right)$. Differences between the capacities of F2N and iron oxides (F3N, F4N, and F3A) may be attributed to differences in particle size, morphology and material composition; the latter potentially being the most significant.

The electrochemical interactions of the active materials with $\mathrm{Li}$ were first investigated through cyclic voltammetry (CV) testing (Fig. 4b-e). In the first five CV cycles, F2N and iron oxide samples reflected the irreversible formation of an SEI layer, and the reversible conversion of Fe between the elemental and cationic oxidation state.

The CV curves for iron oxides (F3N, F4N and F3A), are relatively similar to each other, with the exceptions of reduction peaks observed during the first cathodic sweep, and the rate of current fade upon subsequent cycling. In the first cathodic sweep, four cathodic peaks were present for F3N $(1.55,1.19$, $0.92,0.57 \mathrm{~V})$, while three peaks were seen for F4N $(1.5,0.86$, $0.63 \mathrm{~V})$ and two for F3A $(1.6,0.65 \mathrm{~V})$. The strongest cathodic peak in F3N, F4N, F3A $(0.57,0.63,0.65 \mathrm{~V}$ respectively) can be

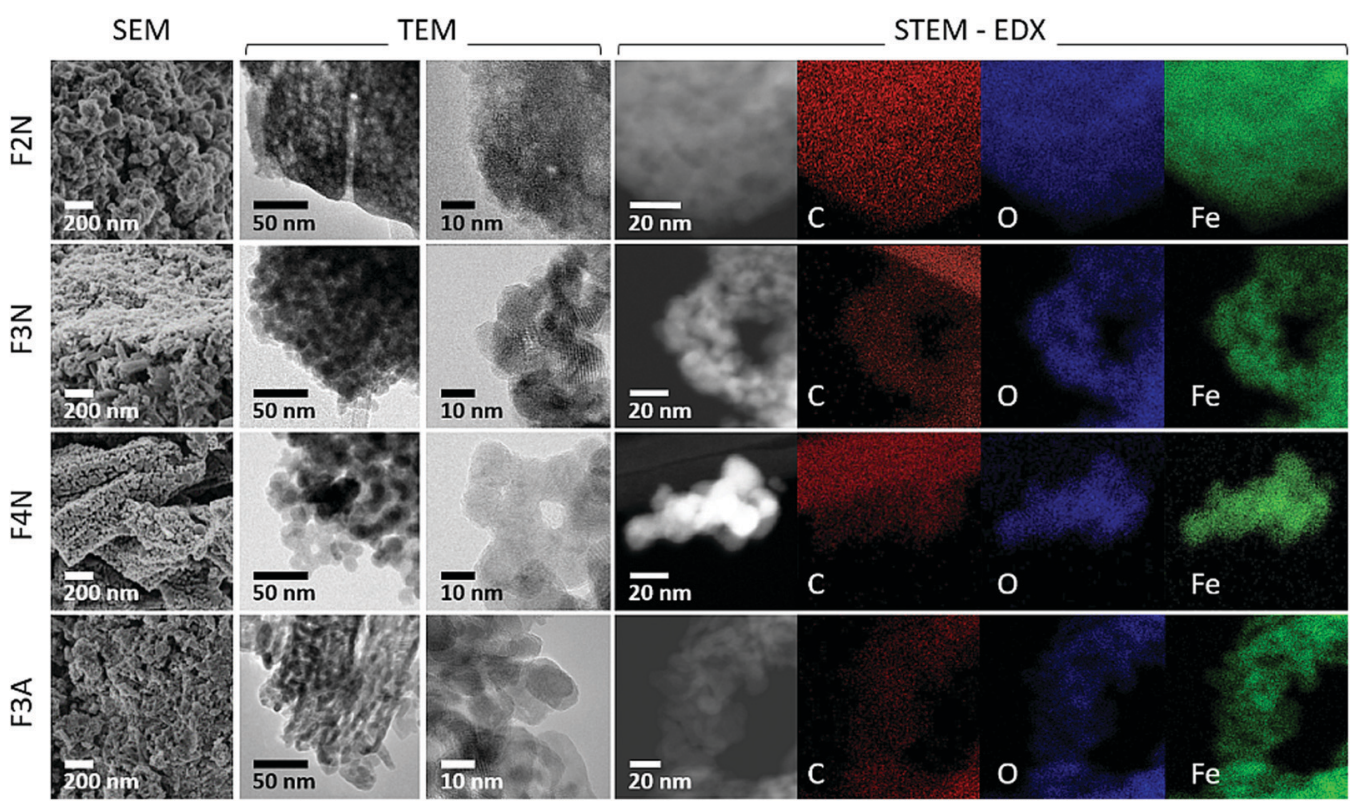

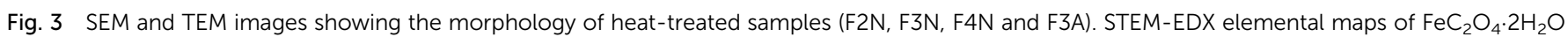
after heat treatment showing the distribution of $\mathrm{C}, \mathrm{O}$ and $\mathrm{Fe}$. 

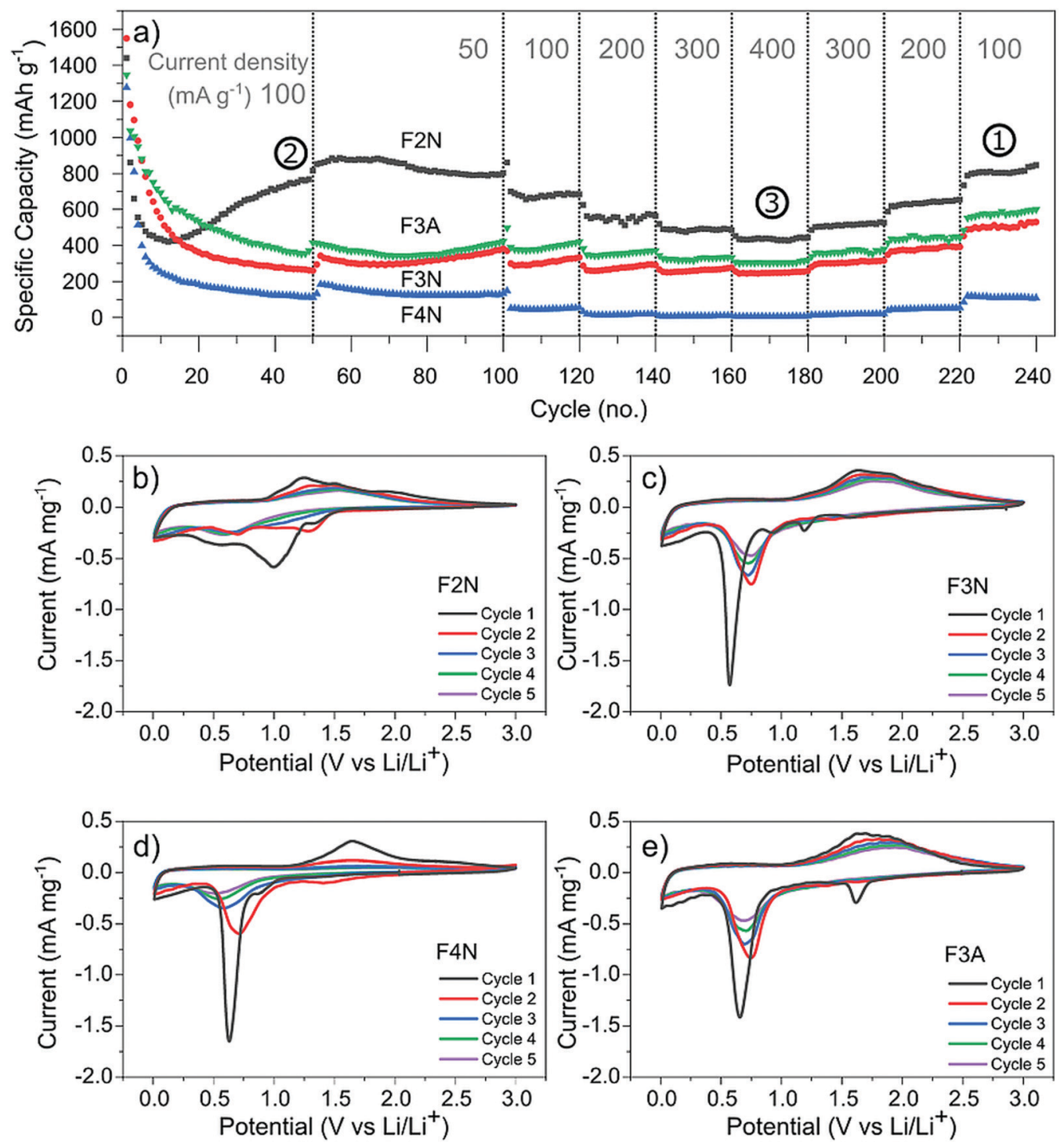

Fig. 4 (a) Discharge capacity of heat-treated samples (F2N, F3N, F4N and F3A) during galvanostatic cycling at 50-400 mA g ${ }^{-1}$ (relative to the active material mass). Specific capacities used for determining carbon content per Ah (Fig. 7) are indicated by the numbers (1, 2, and 3). (b)-(e) Cyclic voltammograms of (b) F2N, (c) F3N, (d) F4N and (e) F3A between 3.0-0.0 V vs. Li/Li at a scan rate of $0.1 \mathrm{mV} \mathrm{s}^{-1}$.

associated with the reduction of Fe cations to $\mathrm{Fe}^{0}$ and irreversible reactions associated with electrolyte decomposition. ${ }^{47}$ The remaining cathodic peaks in the first cycle may be ascribed to the insertion of $\mathrm{Li}^{+}$into $\mathrm{Fe}_{2} \mathrm{O}_{3}$ and irreversible formation of the rock-salt lithiated iron oxides phases. ${ }^{48-50}$ The broad anodic peak arises from the oxidation of $\mathrm{Fe}^{0}$ to $\mathrm{Fe}^{3+}$. This oxidation process occurs in multiple steps, $\mathrm{Fe}^{0}$ to $\mathrm{Fe}^{2+}$ and $\mathrm{Fe}^{2+}$ to $\mathrm{Fe}^{3+}$, with two overlapping peaks visible in the initial cycles. ${ }^{51,52}$ Subsequent cycling resulted in a single redox peak pair attributed to the shuffling of Fe species between the rock salt phase and a composite containing $\mathrm{Fe}^{0}$ and $\mathrm{Li}_{2} \mathrm{O}$.

The first cathodic scan for F2N consisted of three reduction peaks $(1.32,0.99,0.54 \mathrm{~V})$, two of which $(0.99,1.32 \mathrm{~V})$ eventually became absent in subsequent cycles. The third peak, at $0.54 \mathrm{~V}$, shifted to $0.67 \mathrm{~V}$ in the second cycle before shifting back and settling at $0.57 \mathrm{~V}$ in subsequent cycles. Since $\mathrm{Fe}^{0}$ forms when $\mathrm{FeC}_{2} \mathrm{O}_{4}$ reacts with $\mathrm{Li}^{+}$during discharge, ${ }^{12}$ it is likely that the processes occurring during the initial lithiation of iron oxides also occur for $\mathrm{FeC}_{2} \mathrm{O}_{4}$. Hence the cathodic peaks observed may be associated with the insertion of $\mathrm{Li}^{+}$into $\mathrm{FeC}_{2} \mathrm{O}_{4}$ followed by the formation of $\mathrm{Fe}^{0}$ in a matrix of $\mathrm{Li}_{2} \mathrm{C}_{2} \mathrm{O}_{4},{ }^{12}$ and the development of an SEI. ${ }^{13,50,53,54}$ The number of distinct anodic peaks decreased as cycling progressed. Several overlapping peaks appeared in the first cycle, the most prominent ones observed at 1.2, 1.5, $1.9 \mathrm{~V}$ (broad) and at $1.0 \mathrm{~V}$ (shoulder), while two broad peaks were seen in cycle two $(1.3,1.5 \mathrm{~V})$, and one very broad peak at $1.5 \mathrm{~V}$ in subsequent cycles. Anodic peaks arise due to the oxidation of $\mathrm{Fe}^{0}$ particles to oxidation states close to $\mathrm{Fe}^{3+} \cdot{ }^{12}$ The presence of multiple anodic peaks suggests the occurrence of several possible processes including multi-step oxidation, $\mathrm{Fe}^{0}$ to $\mathrm{Fe}^{3+}$ via $\mathrm{Fe}^{2+},{ }^{2,52}$ possible redox reactions involving the oxalate ion, ${ }^{15}$ and irreversible electrolyte reactions. 
Amongst the four materials tested, F4N exhibited the greatest decrease in anodic and cathodic peak currents, along with the largest potential difference between cathodic and anodic peaks. These observations indicate high polarisation effects and irreversibility in the redox reactions, attributed to the large particle size and electrochemical pulverisation. ${ }^{55}$ Both attributions are detrimental to electrode kinetics due to the lower contact area between active materials and electrolyte, and longer $\mathrm{Li}^{+}$diffusion distances. F3N and F3A both showed signs of irreversibility in the form of decreasing cathodic and anodic peak currents, albeit to a lesser extent than F4N. The cathodic peaks for F3N, F4N and F3A shift to a more positive potential in cycle two. This is associated with a reduction in polarisation resistance, most likely due to $\mathrm{Li}^{+}$diffusion being easier after the establishment of diffusion pathways during the first cycle. While the cathodic peak for F3N and F3A observed in cycles 3 to 5 remained at higher potentials than that of cycle 1 , the cathodic peak potential for $\mathrm{F} 4 \mathrm{~N}$ shifts to a more negative value after cycle two, suggesting that subsequent degradation of F4N occurred and led to poorer $\mathrm{Li}^{+}$diffusion kinetics in cycles three to five.

In contrast, cathodic and anodic peak currents for F2N were more consistent after cycle one, indicating greater reversibility. Smaller specific peak currents for F2N compared to iron oxides suggest lower electrochemical activity of $\mathrm{FeC}_{2} \mathrm{O}_{4}$, possibly due to the higher molecular weight (per mole of $\mathrm{Fe}$ ) of $\mathrm{FeC}_{2} \mathrm{O}_{4}$. Differences in molecular structures may also explain the lower oxidation potential observed for $\mathrm{F} 2 \mathrm{~N}$ since the presence of ligands can influence redox potentials of metal cations. ${ }^{56}$

\section{Capacity contributions and trends}

The total capacity observed can be broadly categorised into contributions from processes that are diffusion-controlled and those that occur at or near the surface of the particles, with the latter referred to as capacitive contributions. Processes that are diffusion-controlled include bulk faradaic reactions.

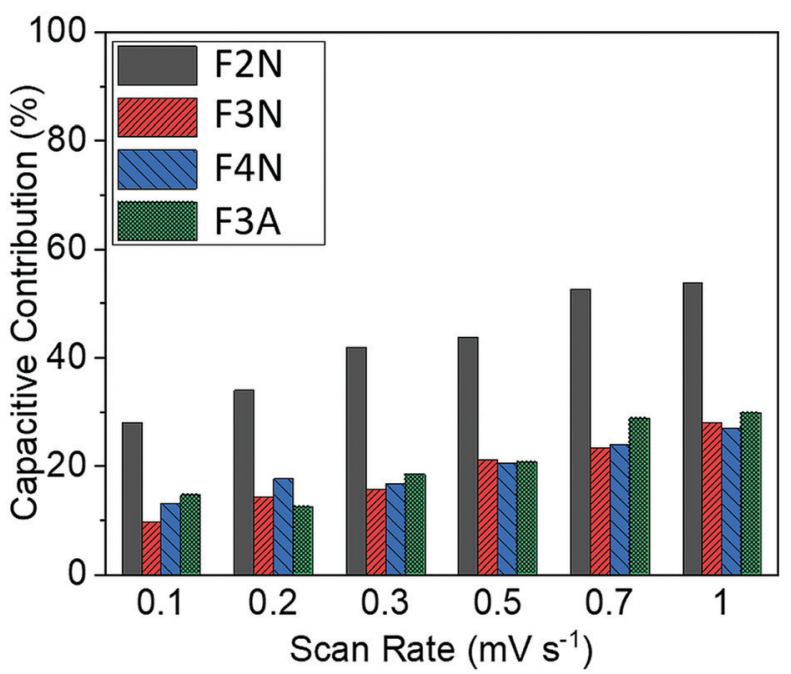

Fig. 5 Capacitive contributions for heat-treated materials at scan rates of 0.1-1 $\mathrm{mV} \mathrm{s}^{-1}$ for F2N, F3N, F4N and F3A.
Fig. 5 summarises the approximate proportion of total capacity contributed to by capacitive processes for each material. The values were estimated via a method reported elsewhere. ${ }^{57,58}$ This method includes performing cyclic voltammetry at different voltage sweep rates $(\nu)$ and is based on the assumption that the total current response at each potential $(i)$ can be described via eqn (3); $k_{\mathrm{c}} \nu$ and $k_{\mathrm{d}} \nu^{1 / 2}$ correspond to current contributions from capacitive and diffusion-controlled processes, respectively.

$$
i(V)=k_{\mathrm{c}} \nu+k_{\mathrm{d}} \nu^{1 / 2}
$$

Results summarised in Fig. 5 suggest that the proportion of capacity contributed to by capacitive processes was the highest for F2N, despite F2N not having the highest BET surface area. This observation may be attributed to the reversible formation of a polymeric gel film which has a possible pseudocapacitive effect. ${ }^{17,18}$ It is possible that the oxalate anions in F2N facilitate the reversible formation of the gel film to a greater extent than the oxide samples, since the oxalate anion contains carboxylate functional groups, which are not too dissimilar from the carbonates present in the electrolyte that react to form the polymeric gel layer, ${ }^{17}$

Discharge capacities of each material varied as cycle number increased, during galvanostatic cycling (Fig. 4). During the initial cycles, capacity fade was observed for all four materials. This decrease has been widely attributed to the formation of an unstable SEI layer and electrochemical pulverisation. ${ }^{59}$ The latter relates to the cracking and crumbling of the active material as a result of structural reorganisation to form separate phases $\left(\mathrm{Li}_{2} \mathrm{O} / \mathrm{Li}_{2} \mathrm{C}_{2} \mathrm{O}_{4}\right.$ and $\left.\mathrm{Fe}^{0}\right)$, and the repeated volumetric expansion and contraction from charging and discharging, leading to particles that are isolated from lithium processes.

After the initial capacity decrease, a prominent increase in capacity was observed for F2N (at ca. cycle 10). Capacity increase was also observed for F3N and F3A at around cycle 70, although this was significantly smaller than F2N. Increasing capacity after the initial decrease has been reported for conversion-type electrodes, and has been attributed to different processes and reactions. ${ }^{17,19,60,61}$ One explanation involves the reversible formation of the polymeric gel film previously mentioned. ${ }^{17}$ The increase in capacity arises from charge transfer processes involved in the reversible formation the polymeric gel layer, and the reactivation of active material in the presence of the polymeric gel layer. ${ }^{17,18,21}$

The larger increase in capacity observed for F2N, compared to iron oxides, may be attributed to a greater extent of polymeric gel layer formation, which potentially stems from the presence of oxalate anions in F2N. The greater extent of polymeric gel layer formation in $\mathrm{F} 2 \mathrm{~N}$ is, as previously mentioned, suggested by $\mathrm{F} 2 \mathrm{~N}$ having the highest capacitive contribution (Fig. 5).

To further investigate capacity trends and contributions, the potential profiles and differential capacity $(\mathrm{d} Q / \mathrm{d} E)$ of each material as cycle number increased were analysed (Fig. 6). Aside from the specific discharge capacity, potential profiles for the oxide samples (F3N, F4N and F3A) were relatively similar. 
a)

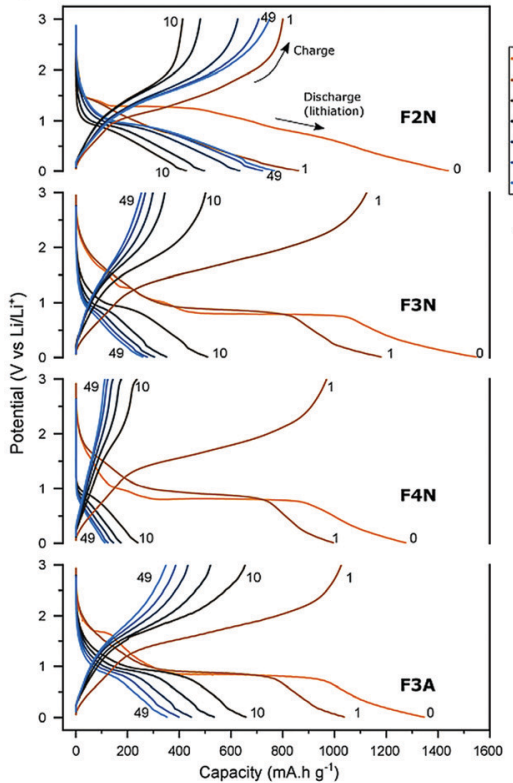

b)

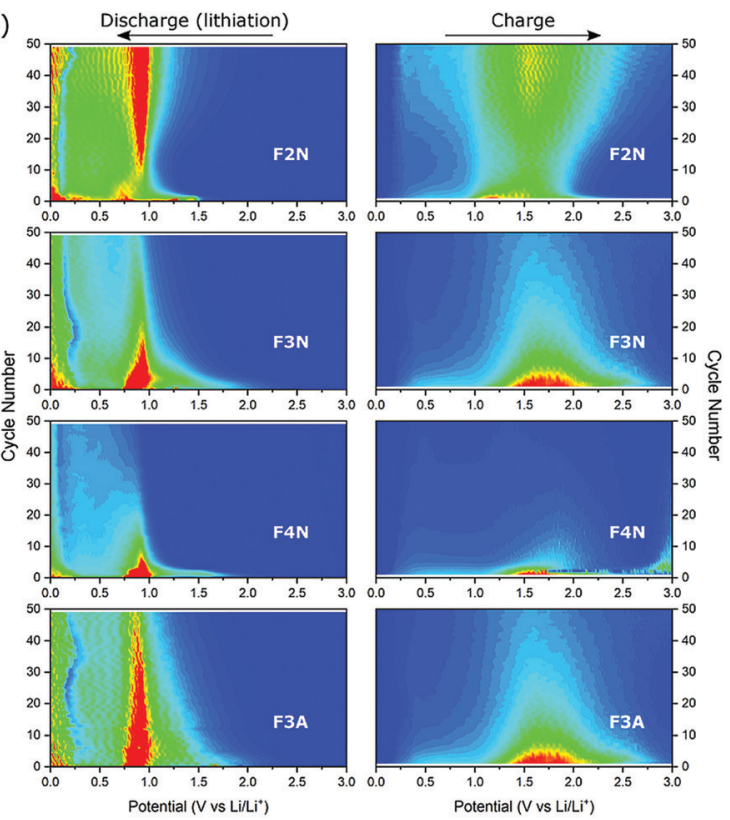

Fig. 6 (a) Potential profiles and (b) differential capacity maps of F2N, F3N, F4N and F3A galvanostatically cycled 50 times at 100 mA g $\mathrm{g}^{-1}$. Differential capacity maps during discharge and charging show the changes to the charge and discharge capacity delivered at each potential as cycling progressed.

The potential profile for the first two discharges (cycle 0 and 1) consisted of a distinct voltage plateau, which can be attributed to the reduction of iron oxide to $\mathrm{Fe}^{0}$ and $\mathrm{Li}_{2} \mathrm{O}$. As the oxide materials were cycled, the voltage plateau during discharge shortened, reflecting a decline in the number of electrons required to reduce iron oxide to $\mathrm{Fe}^{0}{ }^{0 .}{ }^{62}$ This was also reflected in the decrease in differential capacity at all potentials $(0-3 \mathrm{~V})$, particularly at the reduction and oxidation potentials for iron, during charging and discharging. The decline in the quantity of active material undergoing conversion reaction may be partially attributed to the isolation of active material from electrochemical reactions, resulting from particle pulverisation. Another reason includes the inability to fully reverse the conversion reaction due to increased kinetic resistance for $\mathrm{Li}^{+}$migration, resulting from the presence of $\mathrm{Li}_{2} \mathrm{O}$ and an increase in SEI layer thickness, leading to a build-up of $\mathrm{Fe}^{0} .^{50}$

The charging and discharging potential profiles for $\mathrm{F} 2 \mathrm{~N}$ have a more sloping characteristic, and a less prominent voltage plateau from the start, compared to the oxide samples. The potential profile for the first discharge consists of multiple short plateaus; with their presence reflected as regions of high differential capacity (near cycle 0 in Fig. 6b). This matches the multiple cathodic peaks observed during cyclic voltammetry testing. Their presence indicates the occurrence of more electrochemical processes during the first cycle, compared to the oxide samples. As cycling progresses, the discharge potential profile becomes similar to those of the oxide samples, consisting of one short voltage plateau at $c a .0 .9 \mathrm{~V}$ (see cycle 10). In contrast to the oxide samples, the voltage plateau at $0.9 \mathrm{~V}$ becomes more prominent upon further cycling. These changes are more clearly seen as the increases in the differential capacity at potentials associated with the redox reaction of Fe cations ( $c a .0 .9 \mathrm{~V}$ during discharge and $1.5 \mathrm{~V}$ during charging, in Fig. 6b). These suggest that, as cycling progresses, the possibility of a gradual activation of Fe species increases and hence an increase in the number of electrons involved in the conversion reaction.

While electrochemical pulverisation leads to electrical isolation of the active material, resulting in a decrease in capacity, reversible formation of the polymeric gel film may play a role in the recovery and increase in capacity. Further to the additional capacity contributions, the reversible formation of a polymeric gel film has been found to provide mechanical cohesion between the nano-granular conversion reaction products, helping electroactive species to stay within electrical contact, ${ }^{17}$ and impede the agglomeration of particles. ${ }^{18}$ It is therefore possible that, as cycling progresses, the growth or swelling of the polymer gel film links up previously electronically isolated pieces, leading to the gradual reactivation of the active material. Such a proposal would be similar to that reported for metal oxides. ${ }^{21}$

Despite the improved performance of ferrous oxalate compared to oxides derived from oxalates, challenges commonly seen in conversion-type materials are still present. In particular, the sloping voltage profile, especially after substantial cycling, makes it less ideal than a material with a well-defined voltage plateau, as a sloping voltage profile translates to variations in the cell voltage during operation. Further understanding of the high capacities and increases in capacity is also required to determine the long-term impact and stability of the underlying processes.

\section{Carbon and energy storage evaluation}

One intention of the synthesis method reported here was to determine if $\mathrm{CO}_{2}$ can be converted into energy storage materials. 

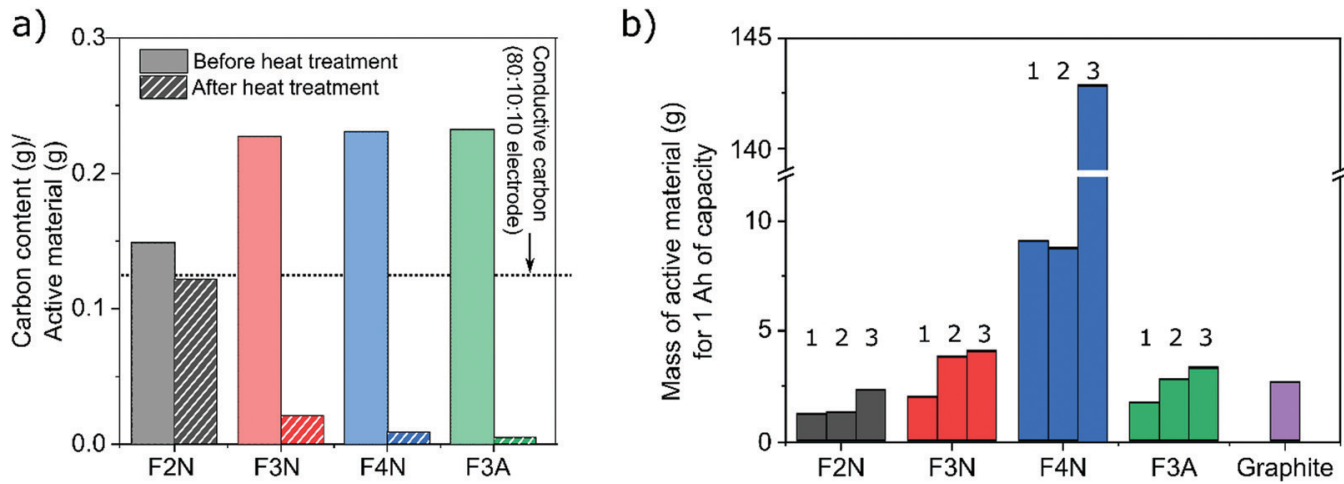

Fig. 7 Carbon content of heat-treated samples. (a) Amount of carbon per gram of heat-treated material before and after heat treatment. (b) Mass of heat-treated material required to store $1 \mathrm{~A}$ h of capacity at three scenarios; (1) cycle 220-240, $100 \mathrm{~mA} \mathrm{~g}^{-1}$, (2) 50th cycle, 100 mA g ${ }^{-1}$, (3) average at $400 \mathrm{~mA} \mathrm{~g}^{-1}$. The value for graphite is provided as a reference, and is based on its theoretical capacity.

The utilisation of $\mathrm{CO}_{2}$ as a means of reducing $\mathrm{CO}_{2}$ emissions may be more effective if the carbon is retained or 'stored' in the product. In this context, a material synthesised from $\mathrm{CO}_{2}$ that has a higher carbon content is therefore more desirable. Meanwhile, a material that has a higher specific capacity is favoured more when considering electrochemical performance. Consequently, both the capacities and carbon content of each material (F2N, F3N, F4N and F3A) were considered when evaluating which material is preferred. For the purpose of this study, only carbon content in the synthesised materials, and carbon released from the materials during heat treatment are considered. All calculations are detailed in the ESI. $\dagger$

F2N showed better prospects as an energy storage material synthesised from $\mathrm{CO}_{2}$, compared to the oxide samples. This arises from the combination of three factors; (1) production of F2N resulted in the least amount of carbon released back into the atmosphere, (2) F2N has the highest carbon content per gram of active material, and (3) F2N exhibiting the largest specific capacity.

The first two points arose from minimal oxalate decomposition achieved at $200{ }^{\circ} \mathrm{C}$ in $\mathrm{N}_{2}$, which also led to less as-isolated $\mathrm{FeC}_{2} \mathrm{O}_{4} \cdot 2 \mathrm{H}_{2} \mathrm{O}$ required to obtain a given mass of heat-treated material. 1.3, 2, 1, and $1 \mathrm{~g}$ of as-isolated $\mathrm{FeC}_{2} \mathrm{O}_{4} \cdot 2 \mathrm{H}_{2} \mathrm{O}$ was required to obtain $1 \mathrm{~g}$ of $\mathrm{F} 2 \mathrm{~N}, \mathrm{~F} 3 \mathrm{~N}, \mathrm{~F} 4 \mathrm{~N}$ and F3A respectively. Considering the amount of carbon in the required quantity of as-isolated $\mathrm{FeC}_{2} \mathrm{O}_{4} \cdot 2 \mathrm{H}_{2} \mathrm{O}$, heat treatment to obtain F2N, F3N, F4N and F3A resulted in 18, 91, 96 and 98\% loss of the 'stored' carbon, respectively (see Fig. 7a).

The second and third points translate to a lower mass of active material required for, and more carbon present in, $1 \mathrm{~A} \mathrm{~h}$ worth of F2N, compared to the oxide samples (see Fig. $7 \mathrm{~b}$ and Table 1). Due to the changes in the discharged capacities observed, calculations were based on three discharge capacities (identified in Fig. 4) for each material; (1) the lowest observed capacity in the last 20 cycles at $100 \mathrm{~mA} \mathrm{~g}^{-1}$ was taken as the reversible capacity at $100 \mathrm{~mA} \mathrm{~g}^{-1}$; (2) capacity recorded at the 50th cycle at $100 \mathrm{~mA} \mathrm{~g}^{-1}$ to negate possible influences of cycling at higher current densities, and; (3) average capacity observed while cycling at $400 \mathrm{~mA} \mathrm{~g}^{-1}$. The amount of active material and carbon content were both considered in this discussion since large quantities of carbon present per ampere-hour of material
Table 1 The mass of carbon present in 1 Ah of heat-treated material; calculated based on specific discharged capacities at (scenario 1) cycle 220-240, $100 \mathrm{~mA} \mathrm{~g}^{-1}$, (scenario 2) 50th cycle, $100 \mathrm{~mA} \mathrm{~g}^{-1}$, and (scenario 3) average at $400 \mathrm{~mA} \mathrm{~g}^{-1}$. The value for graphite is provided as a reference, and is based on its theoretical capacity

\begin{tabular}{llll}
\hline & \multicolumn{4}{l}{ Mass of carbon $(\mathrm{g})$ in $1 \mathrm{~A}$ h of active material } \\
\cline { 2 - 4 } Material & Scenario 1 & Scenario 2 & Scenario 3 \\
\hline F2N & 0.15 & 0.16 & 0.28 \\
F3N & 0.04 & 0.08 & 0.09 \\
F4N & 0.08 & 0.08 & 1.29 \\
F3A & 0.01 & 0.01 & 0.02 \\
Graphite & 2.69 & &
\end{tabular}

can also be achieved in materials with low specific discharge capacities, since more active material is required (see F4N).

The presence of conductive carbon additives in the working electrode was also considered. The quantity of carbon per gram of F2N is comparable to the amount of conductive carbon present in the working electrode, with $0.125 \mathrm{~g}$ conductive carbon per gram of F2N ( $0.12 \mathrm{~g}$ carbon, Fig. $7 \mathrm{a})$ based on the electrode composition used ( $80 \mathrm{wt} \%$ active material $10 \mathrm{wt} \%$ conductive carbon and $10 \mathrm{wt} \%$ polymer binder). While increasing the proportion of conductive carbon decreases the significance of carbon present in the active material, increases to the total amount of carbon per unit mass of working electrode and enhancements in the electrochemical performance of the active material can be expected. However, the mass of conductive carbon must also be accounted for in these future studies, to ensure that the specific capacity of the entire working electrode is not compromised.

While iron oxalate electrodes contain less carbon than graphite-based material, they display capacities larger than the theoretical capacity of graphite. This, coupled with their synthesis from waste scrap steel, demonstrates that oxalates are worthy of further study as sustainable battery materials.

\section{Conclusion}

In the present study, a method to synthesise energy storage materials from carbon dioxide and scrap mild steel was demonstrated. 
Nanostructured anhydrous $\mathrm{FeC}_{2} \mathrm{O}_{4}$ and iron oxides were produced as negative electrode materials in lithium-ion batteries, via an electrochemical process and subsequent heat treatment. Higher heat treatment temperatures resulted in a greater extent of oxalate decomposition into oxides and a lower residual carbon.

Compared to iron oxides prepared at $300{ }^{\circ} \mathrm{C}$ and $400{ }^{\circ} \mathrm{C}$, $\mathrm{FeC}_{2} \mathrm{O}_{4}$ was produced at a lower temperature of $200{ }^{\circ} \mathrm{C}$, leading to greater retention of carbon from the original material. $\mathrm{FeC}_{2} \mathrm{O}_{4}$ also exhibited higher specific capacities, with the enhanced electrochemical performance potentially due to the presence of oxalate anions which facilitates the formation of a reversible polymeric gel layer. Consequently, $\mathrm{FeC}_{2} \mathrm{O}_{4}$ showed more promise as an energy storage material synthesised from $\mathrm{CO}_{2}$, compared to the oxides prepared from oxalates.

While further life cycle analysis of the process and materials would provide a clearer idea of the feasibility of utilising $\mathrm{CO}_{2}$ to produce energy storage materials, the results presented indicate that oxalates may provide a better opportunity as sustainable battery materials than oxides derived from oxalates.

\section{Conflicts of interest}

There are no conflicts to declare.

\section{Acknowledgements}

The authors thank Associate Prof. Yuerui Lu for the use of the tube furnace (SKGL-1200), and Kun Liang and Jian Zhang for their assistance with its operation. The authors also thank Prof. David Nisbet for the use of the Bruker Alpha Platinum-ATR unit, and Stephen Boyer at London Metropolitan University for carrying out $\mathrm{CHN}$ elemental analysis. The authors acknowledge the facilities and the scientific and technical assistance of Microscopy Australia at the Advanced Imaging Precinct, Australian National University, a facility that is funded by the University, State and Federal Governments. The authors acknowledge use of facilities within the Monash X-ray Platform. I. D. B. supported by the FLEET Centre of Excellence, ARC Grant No. CE170100039.

\section{References}

1 D. Larcher and J. M. Tarascon, Nat. Chem., 2015, 7, 19-29.

2 J. M. Tarascon and M. Armand, Nature, 2001, 414, 359-367.

3 M. V. Reddy, G. V. Subba Rao and B. V. R. Chowdari, Chem. Rev., 2013, 113, 5364-5457.

4 S. Guo, G. Lu, S. Qiu, J. Liu, X. Wang, C. He, H. Wei, X. Yan and Z. Guo, Nano Energy, 2014, 9, 41-49.

5 L. Guo, H. Arafune and N. Teramae, Langmuir, 2013, 29, 4404-4412.

6 D. Dollimore, Thermochim. Acta, 1987, 117, 331-363.

7 R. A. Brown and S. C. Bevan, J. Inorg. Nucl. Chem., 1966, 28, 387-391.

8 K. S. Rane, A. K. Nikumbh and A. J. Mukhedkar, J. Mater. Sci., 1981, 16, 2387-2397.
9 P. Niu, T. Wu, L. Wen, J. Tan, Y. Yang, S. Zheng, Y. Liang, F. Li, J. T. S. Irvine, G. Liu, X. Ma and H.-M. Cheng, Adv. Mater., 2018, 30, 1705999.

10 M. Li, W. Wang, M. Yang, F. Lv, L. Cao, Y. Tang, R. Sun and Z. Lu, $R S C A d v$., 2015, 5, 7356-7362.

11 J. S. Yeoh, C. F. Armer and A. Lowe, Mater. Today Energy, 2018, 9, 198-222.

12 M. J. Aragón, B. León, C. Pérez Vicente and J. L. Tirado, Inorg. Chem., 2008, 47, 10366-10371.

13 W. A. Ang, N. Gupta, R. Prasanth and S. Madhavi, ACS Appl. Mater. Interfaces, 2012, 4, 7011-7019.

14 K. Zhang, Y. Li, Y. Wang, J. Zhao, X. Chen, Y. Dai and Y. Yao, Chem. Eng. J., 2020, 384, 123281.

15 W. Yao, A. R. Armstrong, X. Zhou, M.-T. Sougrati, P. Kidkhunthod, S. Tunmee, C. Sun, S. Sattayaporn, P. Lightfoot, B. Ji, C. Jiang, N. Wu, Y. Tang and H.-M. Cheng, Nat. Commun., 2019, 10, 3483.

16 S. Solchenbach, M. Wetjen, D. Pritzl, K. U. Schwenke and H. A. Gasteiger, J. Electrochem. Soc., 2018, 165, A512-A524.

17 S. Laruelle, S. Grugeon, P. Poizot, M. Dollé, L. Dupont and J.-M. Tarascon, J. Electrochem. Soc., 2002, 149, A627-A634.

18 S. Grugeon, S. Laruelle, L. Dupont and J. M. Tarascon, Solid State Sci., 2003, 5, 895-904.

19 K. M. Shaju, F. Jiao, A. Débart and P. G. Bruce, Phys. Chem. Chem. Phys., 2007, 9, 1837-1842.

20 X. Wu, J. Guo, M. J. McDonald, S. Li, B. Xu and Y. Yang, Electrochim. Acta, 2015, 163, 93-101.

21 B. Long, L. Luo, J. Zhang, M.-S. Balogun, S. Song and Y. Tong, Mater. Today Energy, 2018, 9, 311-318.

22 M. C. Rowley, H. Estrada-Medina, M. Tzec-Gamboa, A. Rozin, G. Cailleau, E. P. Verrecchia and I. Green, Plant Soil, 2017, 412, 465-479.

23 G. M. Gadd, J. Bahri-Esfahani, Q. Li, Y. J. Rhee, Z. Wei, M. Fomina and X. Liang, Fungal Biol. Rev., 2014, 28, 36-55.

24 J. Qiao, Y. Liu and J. Zhang, Electrochemical Reduction of Carbon Dioxide: Fundamentals and Technologies, CRC Press, 2016.

25 I. Kaname, I. Shoichiro, Y. Nobuhiro, I. Takaya and T. Takehiko, Bull. Chem. Soc. Jpn., 1985, 58, 3027-3028.

26 I. Shoichiro, T. Takehiko and I. Kaname, Bull. Chem. Soc. Jpn., 1987, 60, 2517-2522.

27 M. König, J. Vaes, E. Klemm and D. Pant, iScience, 2019, 19, 135-160.

28 D. Prat, A. Wells, J. Hayler, H. Sneddon, C. R. McElroy, S. Abou-Shehada and P. J. Dunn, Green Chem., 2016, 18, 288-296.

29 A. R. Paris and A. B. Bocarsly, ACS Catal., 2019, 9, 2324-2333.

30 A. Gennaro, A. A. Isse and E. Vianello, J. Electroanal. Chem. Interfacial Electrochem., 1990, 289, 203-215.

31 W. Lv, R. Zhang, P. Gao, C. Gong and L. Lei, J. Solid State Electrochem., 2013, 17, 2789-2794.

32 M. Jitaru, D. A. Lowy, M. Toma, B. C. Toma and L. Oniciu, J. Appl. Electrochem., 1997, 27, 875-889.

33 R. J. Lim, M. Xie, M. A. Sk, J.-M. Lee, A. Fisher, X. Wang and K. H. Lim, Catal. Today, 2014, 233, 169-180. 
34 P. A. Christensen and S. J. Higgins, J. Electroanal. Chem., 1995, 387, 127-132.

35 U. R. Pokharel, F. R. Fronczek and A. W. Maverick, Nat. Commun., 2014, 5, 5883.

36 R. Angamuthu, P. Byers, M. Lutz, A. L. Spek and E. Bouwman, Science, 2010, 327, 313-315.

37 G.-R. Li, H. Xu, X.-F. Lu, J.-X. Feng, Y.-X. Tong and C.-Y. Su, Nanoscale, 2013, 5, 4056-4069.

38 Y. Yuan and A. Lei, Nat. Commun., 2020, 11, 802.

39 I. Jung, J. Choi and Y. Tak, J. Mater. Chem., 2010, 20, 6164-6169.

40 S. Chenakin and N. Kruse, Appl. Surf. Sci., 2020, 515, 146041.

41 C. Yang, F. Bebensee, J. Chen, X. Yu, A. Nefedov and C. Wöll, ChemPhysChem, 2017, 18, 1874-1880.

42 L. Mazzetti and P. J. Thistlethwaite, J. Raman Spectrosc., 2002, 33, 104-111.

43 M. Hanesch, Geophys. J. Int., 2009, 177, 941-948.

44 A. S. Rajan, S. Sampath and A. K. Shukla, Energy Environ. Sci., 2014, 7, 1110-1116.

45 X. Gao, I. Di Bernardo, P. Kreider, T. Tran-Phu, X. Cai, N. Wang, Y. Zhu, M. B. Venkataraman, J. Lipton-Duffin, A. Bayon, W. Lipiński and A. Tricoli, ACS, Catalysis, 2019, 9, 9880-9890.

46 S.-S. Li, W.-J. Li, T.-J. Jiang, Z.-G. Liu, X. Chen, H.-P. Cong, J.-H. Liu, Y.-Y. Huang, L.-N. Li and X.-J. Huang, Anal. Chem., 2016, 88, 906-914.

47 S. Jin, H. Deng, D. Long, X. Liu, L. Zhan, X. Liang, W. Qiao and L. Ling, J. Power Sources, 2011, 196, 3887-3893.

48 D. Larcher, C. Masquelier, D. Bonnin, Y. Chabre, V. Masson, J.-B. Leriche and J.-M. Tarascon, J. Electrochem. Soc., 2003, 150, A133-A139.
49 L. Wang, Y. Yu, P. C. Chen, D. W. Zhang and C. H. Chen, J. Power Sources, 2008, 183, 717-723.

50 J. Li, S. Hwang, F. Guo, S. Li, Z. Chen, R. Kou, K. Sun, C.-J. Sun, H. Gan, A. Yu, E. A. Stach, H. Zhou and D. Su, Nat. Commun., 2019, 10, 2224.

51 J. Morales, L. Sánchez, F. Martín, F. Berry and X. Ren, J. Electrochem. Soc., 2005, 152, A1748-A1754.

52 M. V. Reddy, T. Yu, C. H. Sow, Z. X. Shen, C. T. Lim, G. V. Subba Rao and B. V. R. Chowdari, Adv. Funct. Mater., 2007, 17, 2792-2799.

53 J. Chen, L. Xu, W. Li and X. Gou, Adv. Mater., 2005, 17, 582-586.

54 D. Larcher, D. Bonnin, R. Cortes, I. Rivals, L. Personnaz and J.-M. Tarascon, J. Electrochem. Soc., 2003, 150, A1643-A1650.

55 D. McNulty, H. Geaney, E. Carroll, S. Garvey, A. Lonergan and C. O’Dwyer, Mater. Res. Express, 2017, 4, 025011.

56 H. Gomathi, Bull. Electrochem., 2000, 16, 10.

57 J. Wang, J. Polleux, T. Brezesinski, S. Tolbert and B. Dunn, ECS Trans., 2008, 11, 101-111.

58 V. Augustyn, P. Simon and B. Dunn, Energy Environ. Sci., 2014, 7, 1597-1614.

59 C. He, S. Wu, N. Zhao, C. Shi, E. Liu and J. Li, ACS Nano, 2013, 7, 4459-4469.

60 Y.-Y. Hu, Z. Liu, K.-W. Nam, O. J. Borkiewicz, J. Cheng, X. Hua, M. T. Dunstan, X. Yu, K. M. Wiaderek, L.-S. Du, K. W. Chapman, P. J. Chupas, X.-Q. Yang and C. P. Grey, Nat. Mater., 2013, 12, 1130.

61 Y. Chai, X. Wang, Y. Yu, X. Shi, Q. Zhang and N. Wang, Int. J. Energy Res., 2019, 43, 6045-6055.

62 D. Puthusseri, M. Wahid and S. Ogale, ACS Omega, 2018, 3, 4591-4601. 